\title{
Population Characteristics of the Mangrove Crab Scylla serrata (Decapoda: Portunidae) in Kosrae, Federated States of Micronesia: Effects of Harvest and Implications for Management ${ }^{1}$
}

\author{
Kimberly M. Bonine, ${ }^{2,3}$ Eric P. Bjorkstedt, ${ }^{4,5}$ Katherine C. Ewel, ${ }^{6}$ and Moses Palik ${ }^{7}$
}

\begin{abstract}
Apparent declines in abundance of mangrove crabs Scylla serrata (Forsskål, 1755) in Kosrae, Federated States of Micronesia, have prompted concern regarding long-term persistence of this important cultural and economic resource. To support development of effective management strategies, we gathered basic biological information about mangrove crabs on this island, where $S$. serrata is the only mangrove crab species present. In particular, we were interested in understanding movement patterns and evaluating spatial variation in population structure. Many population characteristics, including estimated life span, ontogenetic shifts in habitat use, sex-specific allometric relationships, male-biased sex ratios, and evidence for limited $(<2 \mathrm{~km})$ alongshore movement, are similar to those reported elsewhere in the range of the species. Therefore, insights from $S$. serrata populations elsewhere might usefully inform management of the species on Kosrae. Moreover, information reported in this study, for which there is no ambiguity about species identification, has broader relevance. Spatial variation in size structure of the population appears to be driven by variable harvest pressure that reflects distribution of the human population and location of emerging commercial harvest operations. Effective management of mangrove crabs is therefore likely to benefit from application of size-based or sex-based restrictions on harvest and might usefully incorporate spatially explicit strategies, such as partial or complete reserves. Development and implementation of effective management will necessarily depend on cultural as well as scientific information.
\end{abstract}

Mangrove or mud crabs of the genus Scylla are valued as a source of food and income throughout much of the tropical Indo-Pacific and as a consequence have been depleted, in both abundance and size, throughout much of their range (Brown

\footnotetext{
${ }^{1}$ Funding was provided by the MacArthur Foundation initiative on Population, Consumption, and Environment (grant no. 97-49885A-WER to B. Singer, K.C.E., R. Naylor, and S. Abraham) and the USDA Forest Service. Manuscript accepted 14 April 2007.

${ }^{2}$ Institute for International Studies, Center for Environmental Science and Policy, Encina E411, Stanford University, Stanford, California 94305-6055. Current address: Conservation Strategy Fund, 1160 G Street, Arcata, California 95521.
}

Pacific Science (2008), vol. 62, no. 1:1-19

(C) 2008 by University of Hawai'i Press

All rights reserved
1993, Naylor and Drew 1998, Marichamy and Rajapackiam 2001). They occur from India and Southeast Asia to parts of Japan and China and throughout the Pacific islands (Macnae 1968), as an introduced species in Hawai' $i$, and at higher latitudes in Australia and on southern Africa's eastern coast (Hill

\footnotetext{
${ }^{3}$ Corresponding author (phone: 707-822-5505; fax: 707-822-5535; e-mail: kim@conservation-strategy.org.

${ }^{4}$ National Marine Fisheries Service, Southwest Fisheries Science Center, Fisheries Ecology Division, 110 Shaffer Road, Santa Cruz, California 95060.

${ }^{5}$ Department of Fisheries Biology, Humboldt State University, 1 Harpst Avenue, Arcata, California 95521.

${ }^{6}$ USDA Forest Service, Pacific Southwest Research Station, 60 Nowelo Street, Hilo, Hawai'i 96720 . Current address: School of Forest Resources and Conservation, University of Florida, Gainesville, Florida 32611.

${ }^{7}$ Division of Forestry and Wildlife, Kosrae Island Resource Management Authority, P.O. Box DRC, Kosrae State, Federated States of Micronesia 96944.
} 
1974, Heasman et al. 1985). Scylla species are harvested for subsistence throughout their range, are the focus of small- to moderatescale commercial fisheries in some areas, and are farmed commercially in Southeast Asia (e.g., Triño et al. 1999). Despite their importance, little has been done to examine the consequences of harvest for wild populations, especially in developing countries.

On the island of Kosrae, in the Federated States of Micronesia (FSM), Scylla serrata (Forsskål, 1755) (the sole species of mangrove crab present) is one of the most valuable resources extracted from the mangrove forest (Naylor and Drew 1998). These crabs have cultural value as a central part of family feasts and as gifts to expatriates, and economic value derived from export, domestic exchange, and commercial sale to local hotels. Recent socioeconomic studies show that despite apparent declines in catch-per-uniteffort and harvest effort (households engaged in harvest and number of trips per month) during the 1990s, export of crabs for sale and as gifts actually increased substantially, by factors of 8 and 2.5, respectively, from 1997 to 2000 (Naylor and Drew 1998, Naylor et al. 2002). Anticipated economic and human population trends are likely to increase demand for this valuable resource, as well as place greater pressures on the mangrove forests that provide key habitat for the species (Naylor et al. 2002, Hauff et al. 2006). Such trends, and a general sense among Kosraeans that mangrove crabs are becoming increasingly scarce, have raised concerns regarding the sustainability of current harvest levels and persistence of mangrove crabs as a viable and valuable resource.

Scylla serrata is a large portunid crab that can reach a maximum carapace width (CW) well in excess of $200 \mathrm{~mm}$ over the course of a 3- to 4-yr life span (Perrine 1978, Heasman 1980, Robertson 1996). Female S. serrata mature at between 80 and $120 \mathrm{~mm} \mathrm{CW}$ (Hill 1975, Heasman et al. 1985, Prasad et al. 1990, Robertson and Kruger 1994; see also citations in Perrine 1978). Male S. serrata mature physiologically at $90-110 \mathrm{~mm} \mathrm{CW}$ but may not be large enough to compete suc- cessfully for mates until achieving fully adult morphology (e.g., large claws) upon reaching carapace widths of 140-160 mm (Perrine 1978, Heasman et al. 1985, Knuckley 1999). Scylla serrata exhibits sexual dimorphism, with male crabs tending to be heavier than females of similar carapace width (Chakrabarti 1981).

Reproduction occurs year-round in the tropics, with seasonal maxima that appear to coincide with seasonally high rainfall (Le Vay 2001). As in other Scylla species, copulation takes place directly after the female molts and involves an extended period of mate guarding by the male. Ovigerous females swim substantial distances offshorefrom a few to many tens of kilometerswhere the eggs hatch and larvae enter the plankton (Perrine 1978, Hyland et al. 1984, Hill 1994). Repeated spawning by females appears to be possible but has not been demonstrated conclusively (Ong 1966, Perrine 1978, LeVay 2001).

Juvenile $S$. serrata are most common in intertidal habitats, whether on mudflats or in mangroves (Hill 1975, 1978, Hill et al. 1982, Chandrasekaran and Natarajan 1994), moving into deeper habitats as they grow (Hill et al. 1982). Larger male $S$. serrata are commonly found in mangrove channels or in association with burrows located in mangrove forests, on mudflats, or in the banks of channels, as well as on neighboring reef flats (Perrine 1978). These burrows can serve as refugia during low tide and for mating. Female $S$. serrata, on the other hand, are far more commonly found on subtidal reef flats than in the mangrove forest proper (Hill 1975, Perrine 1978, Nandi and Dev Roy 1990), migrating to and from the mangroves to mate, commonly around the time of the new moon (Perrine 1978). Whereas adult crabs may move considerable distances out to sea, previous studies have not found evidence that crabs commonly undertake substantial movements along the coast (Hill 1975, Perrine 1978, Hyland et al. 1984). Most movement on a daily basis occurs at night as crabs move from burrows to channel and reef habitats to forage.

Mangrove crabs have historically been the 
focus of an artisanal fishery on Kosrae, with almost all crabs being captured by removal from burrows by hand or with simple tools, by "torch fishing," which entails walking the reef flats at night during low tides seeking crabs and other target species, with baited lines and more recently with baited traps (Perrine 1978, Smith 1992). Most households on Kosrae harvest crabs from nearby mangrove forests, but larger-scale family-based commercial fisheries emerged in the 1990s in Tafunsak and Utwe, where they are said to have substantially increased harvest rates (Naylor et al. 2002). Before this study, there was no restriction on mangrove crab harvest, but a minimum size limit for retention of 6 inches $(152 \mathrm{~mm})$ was enacted in 2000 . In contrast to many fisheries on relatively longlived, large crustaceans in North America, Australia, and elsewhere, in which harvest is restricted to males, female crabs-including those bearing eggs—are commonly retained on Kosrae (Naylor et al. 2002).

In this paper we report on a study conducted between October 1998 and May 2001 on the island of Kosrae, Federated States of Micronesia, to provide information on population characteristics of $S$. serrata from which inferences regarding population dynamics and the effects of harvest can be drawn. The goal of this effort is to inform development of management strategies that will ensure continued availability of mangrove crabs, yet are simple for local resource managers to implement and evaluate.

\section{MATERIALS AND METHODS}

Study Area, Arrangement of Sampling Locations, and Description of Habitats Sampled

Kosrae $\left(5^{\circ} 19^{\prime} \mathrm{N}, 163^{\circ} 00^{\prime} \mathrm{E}\right)$ (Figure 1) is a high volcanic Pacific island $113 \mathrm{~km}^{2}$ in area, much of which is steep forested mountains that are surrounded by a narrow coastal plain and a fringing coral reef. The climate is moist and hot, with little interannual variation in rainfall $(5,000-7,000 \mathrm{~mm}$ per year) or temperature (annual average ca. $27^{\circ} \mathrm{C}$ ). Diverse, intact mangrove forests cover approximately
1,562 ha and line two-thirds of the coastline (Whitesell et al. 1986, Ewel et al. 2003). The island is divided into four municipalities (Tafunsak, Lelu, Malem, and Utwe), each with a variety of villages and settlements. At the time of this study, the population of Kosrae was ca. 7,700 (FSM Census 2002), most of whom lived on the narrow coastal plain along the northern, eastern, and southern sides of the island. The largest population concentrations are in Lelu Island and the village of Tafunsak. Smaller settlements lie along the road connecting the two, as well as farther along the road in Malem and Utwe. A village on the western part of the island (Walung, in the municipality of Tafunsak) was, at the time of this study, reachable only by boat.

As part of a broader study of resource use in the mangrove forests of Kosrae, the island's coast was divided into nine sectors based on the position of rivers and population centers (Hauff et al. 2006). We focused much of our sampling effort in four of these sectors: Lelu Harbor and Pukusrik in the municipality of Lelu, Okat in the municipality of Tafunsak, and a long stretch of coastline extending from the village of Utwe to the settlement of Isra, both in the municipality of Utwe (Figure 1). Additional collections were made near Walung and the settlement of Yemulil in the municipality of Utwe, farther WNW along the coast from Isra; the data from those sites are used in a more limited manner due to differences in the habitat types from which the crabs were collected.

Although the overall species composition of the mangrove forests shows little systematic spatial variation around Kosrae (Ewel et al. 2003), those forests close to population centers or easily accessible by roads experience higher rates of removal of mangrove wood. Extensive logging often selectively removes valued tree species and generates large gaps that may not be recolonized by mangrove hardwoods (Hauff et al. 2006). Our Lelu Harbor and Okat sites were similar in that the mangroves in both areas formed a more or less continuous strip between uplands and reef flats, penetrated occasionally by relatively narrow river channels (Figure 


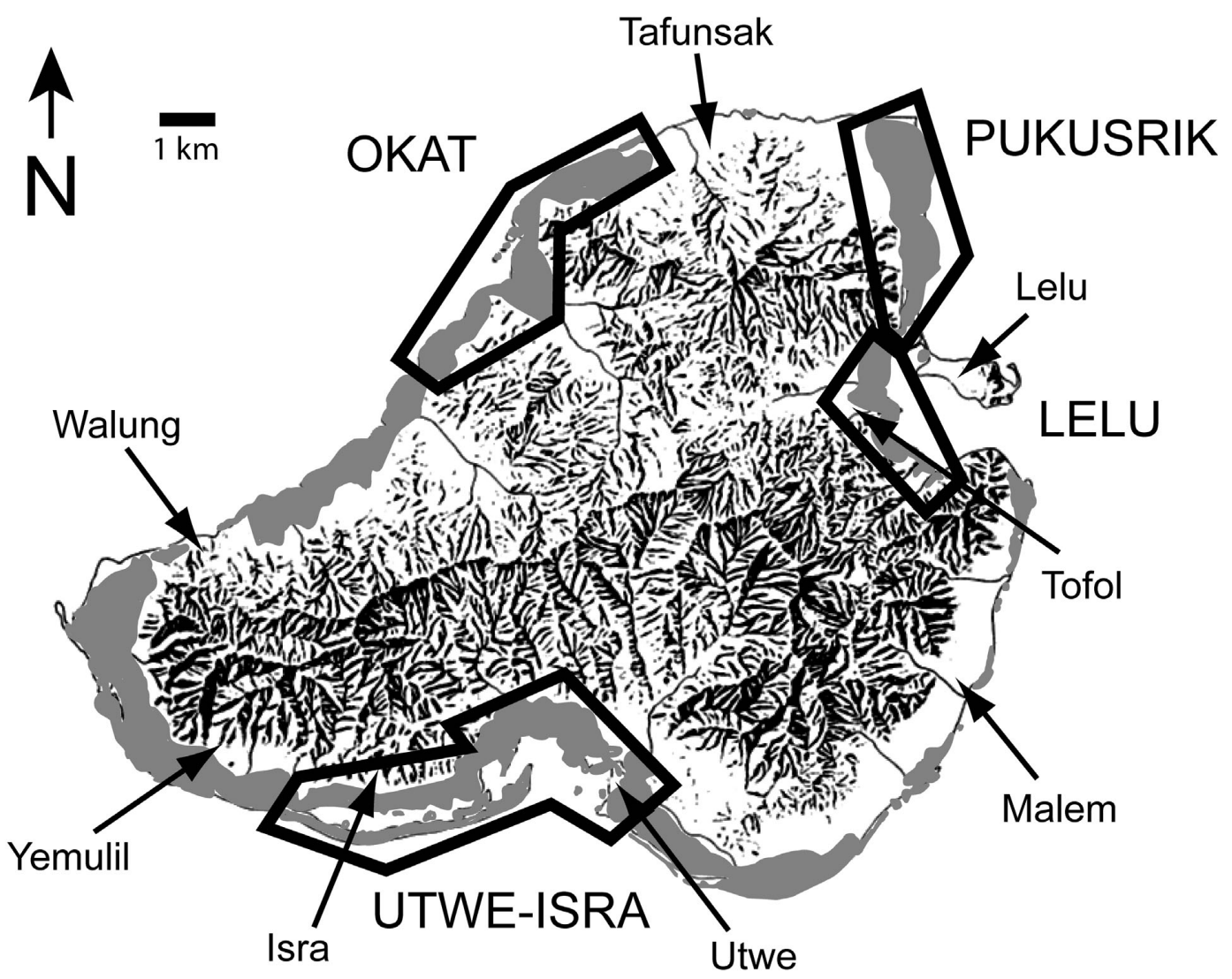

Figure 1. Map of Kosrae, Federated States of Micronesia, showing general distribution of mangrove forests (in gray), boundaries of sectors defined in text (all capital letters), and location of villages and other settlements mentioned in text.

1). In contrast, the mangrove forests at the Pukusrik and Utwe-Isra sites were both bounded on the seaward side by berms of coral sand, containing broad tidal channels connected to a larger bay through relatively narrow gaps (Figure 1). The channel at Utwe-Isra included substantial reef habitats. The mangrove forest in Puksurik rested on sandier soil and contained springs in several places. This mangrove forest was also shorter, probably reflecting a long history of smallscale harvesting.

We stratified the mangrove forests where we sampled mangrove crabs into three zones: (1) "fringe," which lay within $100 \mathrm{~m}$ of the seaward margin of the mangrove forest and might be separated from the open ocean by reef flat or beach strand; (2) "riverine," which lay within $150 \mathrm{~m}$ of a riverbank; and (3) "interior," which included the remainder of the mangrove forest not part of the previous two zones (Hauff et al. 2006). Because the relative extent of each of these zones varied from sector to sector and either the fringe or riverine zone was entirely lacking in some areas (Hauff et al. 2006), we focused most of our sampling in interior mangrove forests. Constraints arising from accessibility and our primary method of sampling (traps) prevented us from sampling areas of the mangrove forest close to the landward margin or in slightly elevated areas between channels. 
Crab Sampling and Estimation of Catch-perUnit-Effort

We used baited traps as our primary method of collecting $S$. serrata but also collected crabs opportunistically by hand during surveys of the mangrove forest. All crabs, regardless of method of capture, were measured (carapace width in millimeters), weighed (to the nearest 0.1 kilograms), and identified by sex.

Traps had approximate dimensions of 1.2 by 0.6 by $0.3 \mathrm{~m}$, were fitted with $2.5-\mathrm{cm}$ wire mesh, and were baited with one or more types of bait (e.g., tuna, shark, reef fish, pig remains, etc.). In a typical set, six to eight traps were deployed at intervals $\geq 20 \mathrm{~m}$ along the length of a channel through the mangrove forest. Traps were deployed at arbitrarily selected locations in waterways accessible to a small motor skiff where crabs were expected or known to occur. Effort concentrated on collecting a representative sample from the sector but was not directed according to a formal randomized sampling design. Traps were checked daily, after having fished a complete flood-ebb tidal cycle, and were typically fished for 2-4 consecutive nights at a given location.

Over the course of implementing our sampling program, it became apparent that tuna was clearly the most effective bait, and we switched to its use exclusively. To estimate catch-per-unit-effort, we used only data collected from traps that were baited with tuna and deployed in interior channels.

\section{Tagging Study}

All crabs captured were marked by affixing a series of six roughly cylindrical glass beads (flat side down, hole oriented vertically) to the center of the carapace with cyanoacrylate glue and released at the point of capture. Each crab received a unique combination of colored beads to allow identification upon recapture. Local crab harvesters were encouraged through various outreach efforts to report the day, location, and bead color sequence of any tagged $S$. serrata captured in the course of normal harvesting. In the few cases where a crab was returned missing a single bead of the six, identification was accomplished using the remaining beads and the individual's carapace width.

\section{Statistical Analysis and Demographic Modeling}

To estimate catch-per-unit-effort, we defined effort as a single trap fished at a particular location for one night and calculated catchper-unit-effort as the number of crabs trap ${ }^{-1}$ night $^{-1}$, modeled as a Poisson process. We assumed that traps were fishing independently and evaluated this assumption by examining mean catch-per-unit-effort as a function of the number of traps in a set as well as mean catch-per-unit-effort as a function of trap position within a set.

We estimated allometric relationships between carapace width ( $L$, in millimeters) and weight ( $W$, in kilograms) by fitting models of the form $W=\alpha L^{\beta}$ using standard nonlinear regression techniques. Size data for all captured crabs were included in the analysis. Based on preliminary examination of the data, separate models were fit for male and female crabs. Preliminary examination of individual condition $\left(W L^{-3}\right)$ suggested that among both male and female crabs a small subset of individuals existed whose weight clearly exceeded the range typical of the population at a given carapace width. We therefore divided the population using an (arbitrary) threshold condition of $2.8 \times 10^{-7}$ $\left(\mathrm{kg} \mathrm{mm^{-3 }}\right)$ and fit separate allometric relationships for each group within each sex.

To identify size classes, we binned carapace widths for all crabs in our data set at $4 \mathrm{~mm}$ intervals over the range of $80 \mathrm{~mm}$ to $220 \mathrm{~mm}$ and applied Hasselblad's (1966) steepest-descent algorithm for estimating the parameters of a mixture of normal distributions. We used two-sample KolmogorovSmirnov (K-S) tests to compare distributions of carapace width among subsets of the data based on zone, sector, or sex. In addition, distributions of carapace width for subsets of the data were compared visually to the overall distribution of size classes to evaluate representation of size classes within subsets of the 
population. We estimated Hiatt's (1948) relationship for sequential size classes by fitting the model $L_{i+1}=c+d L_{i}$ to the estimated mean carapace widths $\left(L_{i}\right)$ for each size class using least-squares regression.

We developed crude estimates of migration distance for tagged crabs based on the location of release and recovery. Because location data were often imprecise, we were able to quantify movement at a spatial scale on the order of a few kilometers (i.e., to resolve movement between sectors but with little precision within sectors).

Because tags are lost when a crab molts, the longest period that an individual is known to retain a tag (i.e., the maximum interval between the release and recovery of a tagged individual) provides a lower bound on the intermolt interval. The longest of these intervals therefore provides a measure of the intermolt interval. To estimate minimum intermolt intervals ( $I$ in days) as a function of carapace width ( $L$ in millimeters), we fit a model of the form $I=\exp \{a+b * L\}$ subject to the following constraints: (1) all observed intervals between release and recapture of a tagged crab had to fall below model predictions, and (2) the smallest difference between predicted and observed releaserecapture intervals was to be minimized. This model has a structure similar to constant-ratio patterns in intermolt intervals reported for other crustacean species (Caddy 2003) but instead relates intermolt interval to individual size. Because estimation of extrema is sensitive to sampling effort, and the smallest crabs are apparently less susceptible to capture, we corroborated this analysis with data reported by Arriola (1940) for intermolt periods observed for two mangrove crabs reared in captivity and a single field measurement of an intermolt interval reported by Perrine (1978); however, these data were not included with those used to fit the model.

We used information obtained on intermolt intervals and size-class distributions to construct a simple model for estimating rates of attrition affecting the population of mangrove crabs susceptible to capture in our sampling program, under the assumptions that recruitment and average size-specific molting rates of mangrove crabs do not vary around the island. By attrition, we mean the combined effects of natural mortality, mortality due to harvest, and any size-specific migration to or from the sampled habitat (e.g., emigration by larger crabs from interior channels of the mangrove forest to more subtidal habitats). To avoid confounding our analysis with variation in size distributions and sampling effort related to habitat type, we used only observations collected with traps set in interior channels.

A detailed description of the model, its construction, and our analytical approach are provided in the Appendix and are summarized here for convenience. The model describes the development of size-class frequency distributions according to the rates of transitions among size classes in a stagestructured population and, based on these dynamics, estimates attrition rates necessary to yield predicted size-class frequency distributions that match our observations. We defined the daily probability of an individual's making the transition from one stage to the next as the inverse of the intermolt interval predicted for the mean carapace width of each size class. We lacked the full complement of information necessary to construct a credible density-dependent model. We therefore assumed that any densitydependent mechanisms affect the population dynamics in such a way that a stable steady state exists and that the stable size-class distribution achieved at this steady state is identical to that reached under density-independent dynamics with $R=1$ (i.e., a constant population size) (Caswell 2001). Because crabs in smaller size classes (less than ca. $130 \mathrm{~mm}$ carapace width) were either less available or less susceptible to capture in our traps, we included size class-specific catchability in the process of fitting model-predicted stable size-class distributions to the data. Preliminary inspection of the size-class distributions also indicated that attrition rates affecting smaller size classes might differ from those affecting larger size classes, so we fit models that estimated attrition rates separately for 

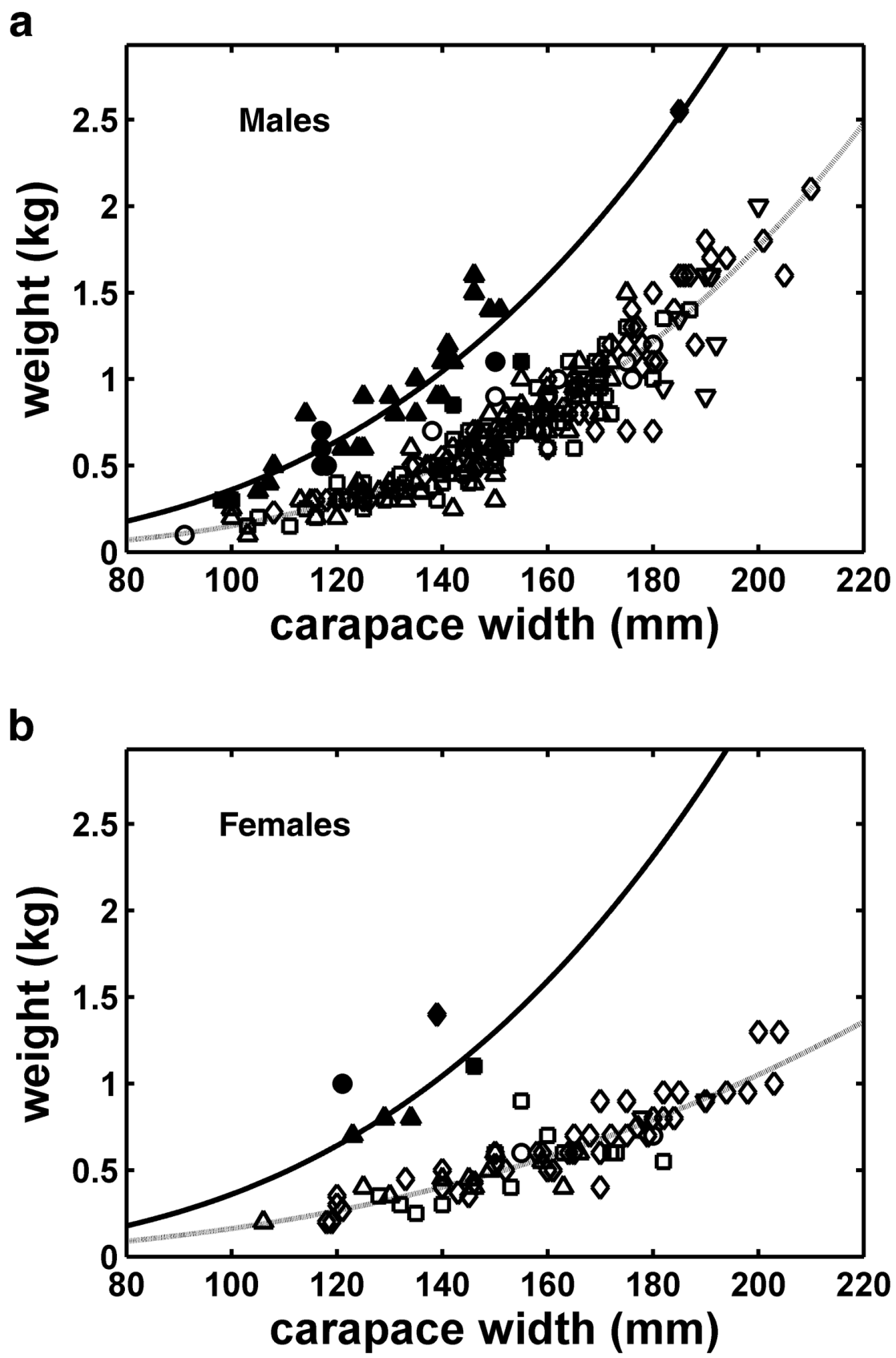

FigURE 2. Allometric relationships between carapace width $(\mathrm{mm})$ and weight $(\mathrm{kg})$ for $(a)$ male and $(b)$ female mangrove crabs (Scylla serrata) on Kosrae, FSM. Open circles are for "light" crabs and filled circles are for "heavy" crabs, defined according to a condition threshold; see text for details. Lines indicate allometric relationships between weight $(W)$ and carapace width $(L)$ of the form $W=\alpha L^{\beta}$; parameter values in Table 1; we plot the relation for "heavy" males in $(b)$ for comparison to "heavy" females. Symbols indicate sector: Lelu (०), Pukusrik ( $\square$ ), Okat $(\triangle)$, Walung/Yemulil $(\nabla)$, Utwe-Isra $(\diamond)$. 
TABLE 1

Allometric Relationships between Carapace Width $(L$, in $\mathrm{mm})$ and Weight $(W$, in $\mathrm{kg}$ ) Estimated by Fitting Models of the Form $W=\alpha L^{\beta}$ for Groups of Mangrove Crabs from Kosrae

\begin{tabular}{lrlc}
\hline \hline Group & $n$ & $\alpha(95 \% \mathrm{CI})$ & $\beta(95 \% \mathrm{CI})$ \\
\hline Normal males & 218 & $3.54(3.36,3.73)$ & $1.23 \times 10^{-8}\left(4.14 \times 10^{-10}, 2.42 \times 10^{-8}\right)$ \\
"Heavy" males & 37 & $3.16(2.78,3.54)$ & $1.73 \times 10^{-7}\left(-1.51 \times 10^{-7}, 4.96 \times 10^{-7}\right)$ \\
Normal females & 72 & $2.69(2.36,3.02)$ & $6.81 \times 10^{-7}\left(-4.85 \times 10^{-7}, 1.85 \times 10^{-6}\right)$ \\
"Heavy" females & 6 & $1.94(-2.23,6.11)$ & $7.38 \times 10^{-5}\left(-1.59 \times 10^{-3}, 1.72 \times 10^{-3}\right)$ \\
\hline
\end{tabular}

Note: Point estimates are followed in parentheses by upper and lower bounds on $95 \%$ confidence intervals for the estimated parameters.

sets of contiguous size classes designated on the basis of apparent breaks in the size-class distribution.

\section{RESULTS}

\section{Life History and Population Characteristics}

SEx ratio. Overall, male $S$. serrata outnumbered females (3.3:1, $n=357$, total) regardless of method of capture (trap: $3.2: 1$, $n=339$; opportunistic capture by hand: $5: 1$, $n=18$ ). The sex ratio varied significantly by sector; bias toward males in our samples was substantially lower $(1.81: 1, n=90)$ in UtweIsra than elsewhere (Lelu Harbor: 6.00:1, $n=21$; Pukusrik: $4.92: 1, \quad n=83$; Okat: $5.87: 1, n=103)$. None of the captured females was ovigerous.

allometric relationships. Allometric relationships for male crabs differed significantly from those for female crabs, with male crabs tending to be heavier than females for a given carapace width (Figure 2, Table 1). For both male and female crabs, we observed a distinct subset of individuals that were approximately twice as heavy as most other crabs for a given carapace width, a trait more commonly observed among male crabs (37 of 255 were "heavy" [14.5\%]) than females (6 of 78 [7.7\%]) (Figure 2, Table 1). Sample size limited our ability to estimate the exponential term of the allometric relationship for all but the lighter subset of male crabs, but visual inspection strongly suggests that a power-law adequately describes the data (Figure 2, Table 1). Heavy females were too rare to allow a robust allometric relationship to be developed and were not significantly differentiable from any other group, but qualitative examination suggested that they were in the same range as heavy males and exhibited a similar allometric relationship (Figure 2). We detected no significant differences among sectors in the allometric relationships between carapace width and weight for either male or female crabs, but this analysis had limited power due to small sample sizes.

SIZE STRUCTURE AND SUSCEPTIBILITY to capture. Mangrove crabs exhibited distinct size classes with little overlap (Figure 3). The progression of mean carapace widths was described by a linear relationship of the form $L_{i+1}=c+d L_{i}$ (Hiatt 1948) with $c=29.721 \quad(95 \%$ CI: $16.565,42.878)$ and $d=0.912$ (95\% CI: $0.825,0.998)$. Male and female crabs exhibited similar size classes, and the overall size distribution of crabs did not differ significantly between sexes (K-S test, $P=0.31)$. The size-frequency distribution of crabs in our samples suggested that the smallest crabs susceptible to capture in our traps were ca. $100 \mathrm{~mm}$ in carapace width and that susceptibility to capture increased with size.

STAGE DURATION AND ESTIMATED LIFE SPAN. Eighty $S$. serrata were recaptured during the course of our study, 12 of which were at large for at least 1 month after being tagged and released. The maximum observed interval between release and recapture (I in days) increased with carapace width ( $L$ in millimeters) according to $I=\exp \{0.009+$ $0.0314 * L\}$ (Figure 4), which is consistent 


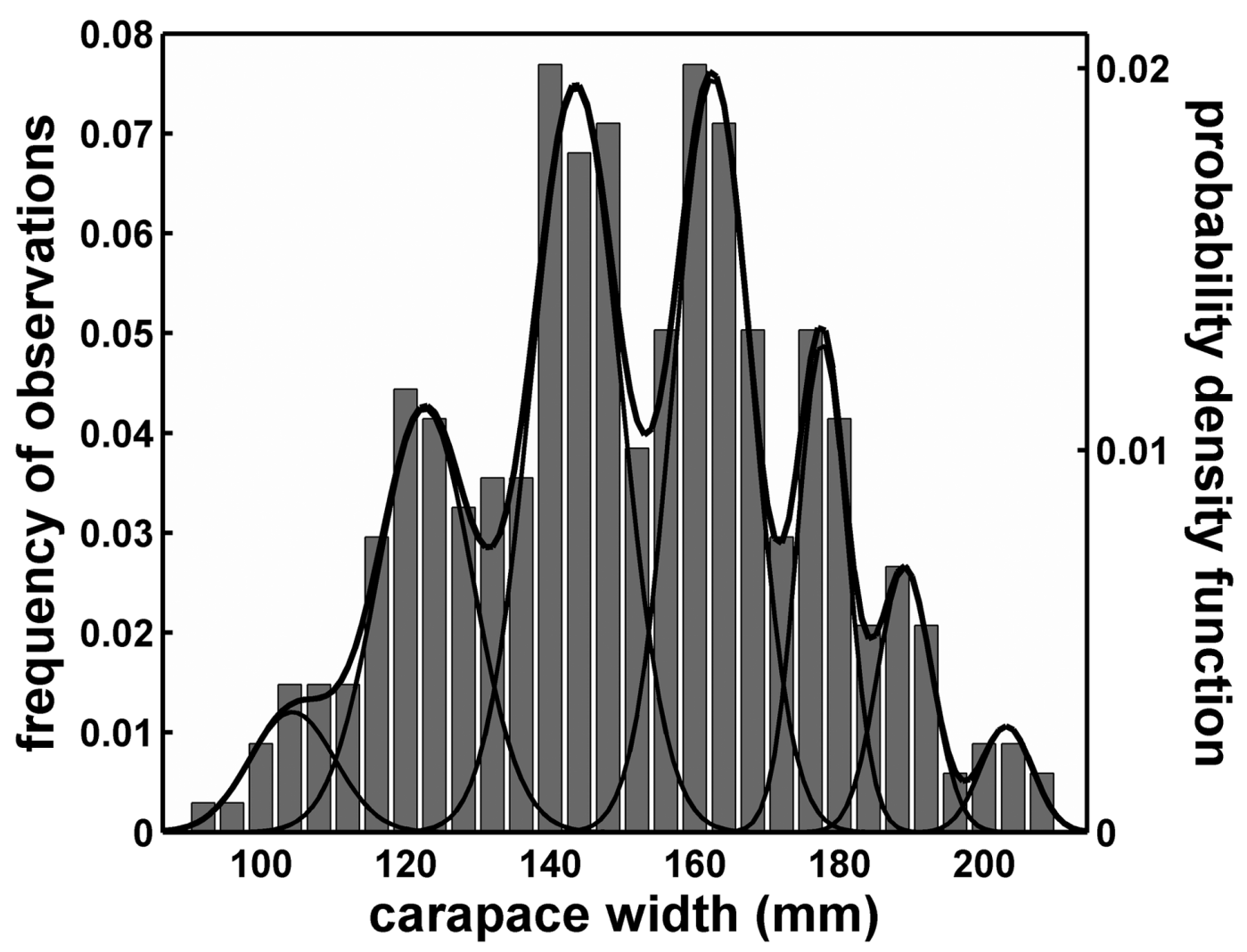

FiguRE 3. Size classes, based on carapace width, of trap- and hand-caught mangrove crabs (Scylla serrata) on Kosrae, FSM. Bars (scale on left $y$-axis) indicate observed frequency of crabs in $4 \mathrm{~mm}$ size bins. Thin lines (scale on right $y$ axis) indicate normal distributions that correspond to size classes with mean (SD), in mm, of 104.3 (5.9), 122.6 (6.6), 143.5 (6.2), 162.4 (5.4), $177.6(3.4), 189.0$ (3.7), and 203.1 (3.6). Size class distributions are scaled by the proportional representation of each size class in the sample. Thick line shows the composite distribution for the population, formed as the sum of the scaled size class-specific normal distributions.

with a pattern of increasingly long intermolt intervals over the course of a typical crustacean life cycle. Information on intermolt intervals for two crabs reared in captivity and two field observations suggests that our model also holds for the smaller size classes in our data set (Figure 4) (Arriola 1940, Perrine 1978).

To estimate the life span of $S$. serrata on Kosrae, we assumed that (1) the largest crabs observed in our study are representative of the maximum size attained by $S$. serrata on Kosrae, and (2) on average, an individual crab requires 6 months to grow to the smallest size class observed in this study (Arriola
1940, Ong 1966), after which our data suggest a minimum period of 979 days (ca. 2.7 yr) to reach the largest observed size class.

dispersal patterns. Almost all (79 of 80) recaptures occurred in the same sector where the crab was initially captured or last observed, including four of five crabs at large for more than 100 days. Crabs that remained within a sector traveled no more than ca. 2 to $3 \mathrm{~km}$, and it is likely that most distances were substantially smaller (i.e., $<1 \mathrm{~km}$, based on descriptions of release and recapture locations). One male crab (166 mm CW) moved ca. $8.5 \mathrm{~km}$ from Walung to Okat during 174 days at large. 


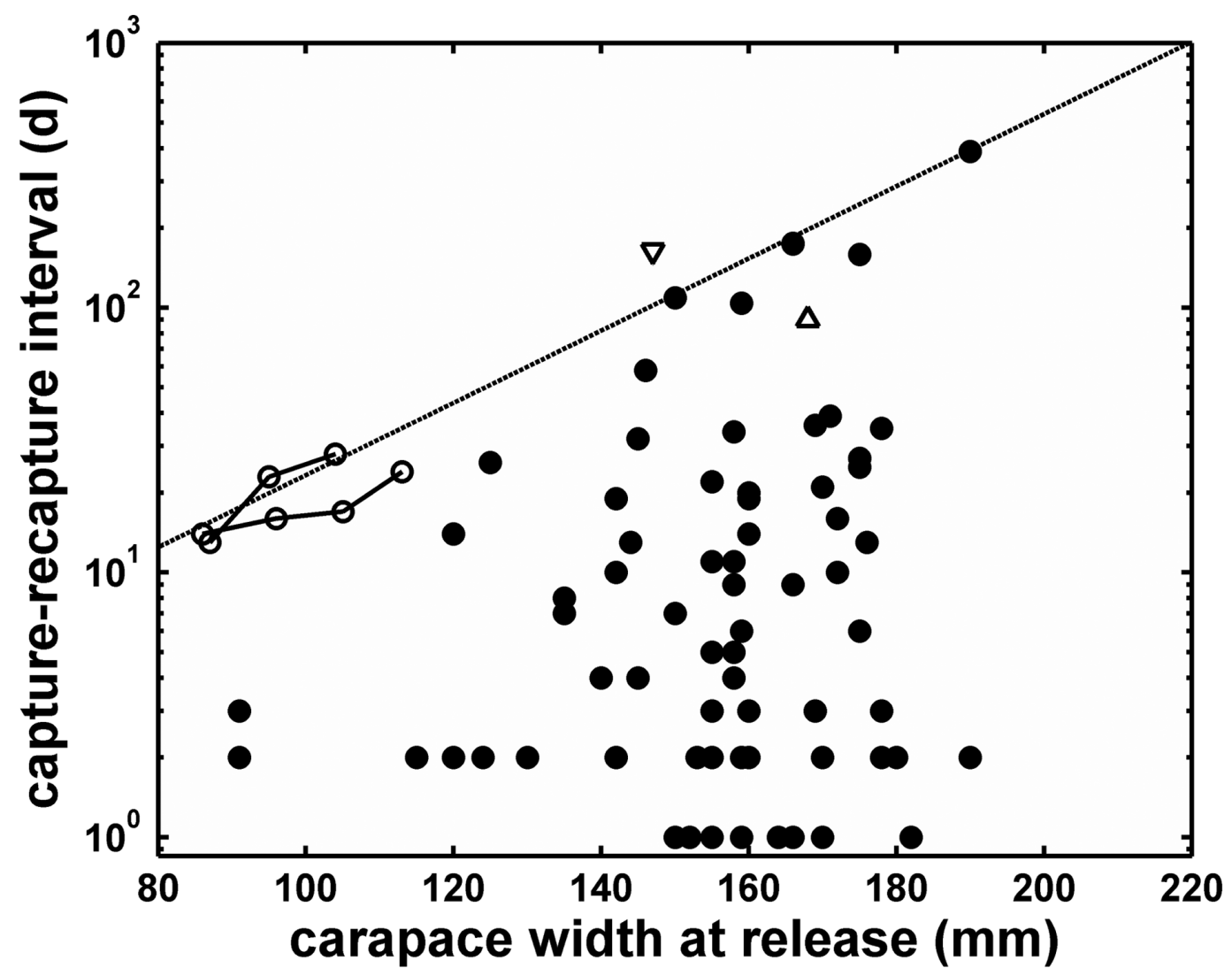

FIgURE 4. Release-recapture intervals for mangrove crabs as a function of carapace width. Closed circles indicate intervals for mangrove crabs tagged and released as part of this study. Open circles connected by solid lines indicate sequential intermolt intervals observed for a pair of mangrove crabs reared in captivity (Arriola 1940). Triangles indicate intervals at large for tagged crabs that molted $(\triangle)$ and did not molt $(\nabla)$ reported by Perrine (1978). Dotted line indicates "minimum" intermolt interval (see text for description of fitting method) inferred from the tagging experiment reported here; data from Arriola (1940) and Perrine (1978) are not used in this analysis and are presented only to corroborate the model at smaller size classes.

\section{Spatial Variation in Population Characteristics}

Size structure of mangrove crabs varied across the landward-seaward axis of the mangrove forest, as well as among sectors around the island (Figure 5). Crabs captured in traps deployed in fringe channels (near the edge of the mangrove forest) were significantly larger than crabs trapped in other zones of the forest (Figure 5): Utwe-Isra: K-S test, $P<0.001$ (males), K-S test, $P=0.0058$ (females); all sectors: K-S test, $P<0.0001$ (males), K-S test, $P<0.0001$ (females).

Size distributions for crabs captured in interior channel habitats differed significantly among sectors (K-S test: Pukusrik versus Utwe-Isra, $P=0.0124$; Pukusrik versus Okat, $P=0.0007$; Utwe-Isra versus Okat, $P<0.00001$ ), and these patterns reflect spatial variation in proportional representation of size classes (Figure 6). The dominant size class observed in Utwe-Isra $(178 \mathrm{~cm})$ was almost absent in Pukusrik and Okat, where the dominant size classes were centered at $162 \mathrm{~cm}$ and $144 \mathrm{~cm}$, respectively (Figure 6). These patterns were reflected in separate comparisons for male and female crabs (results not shown), although the significance of the dif- 


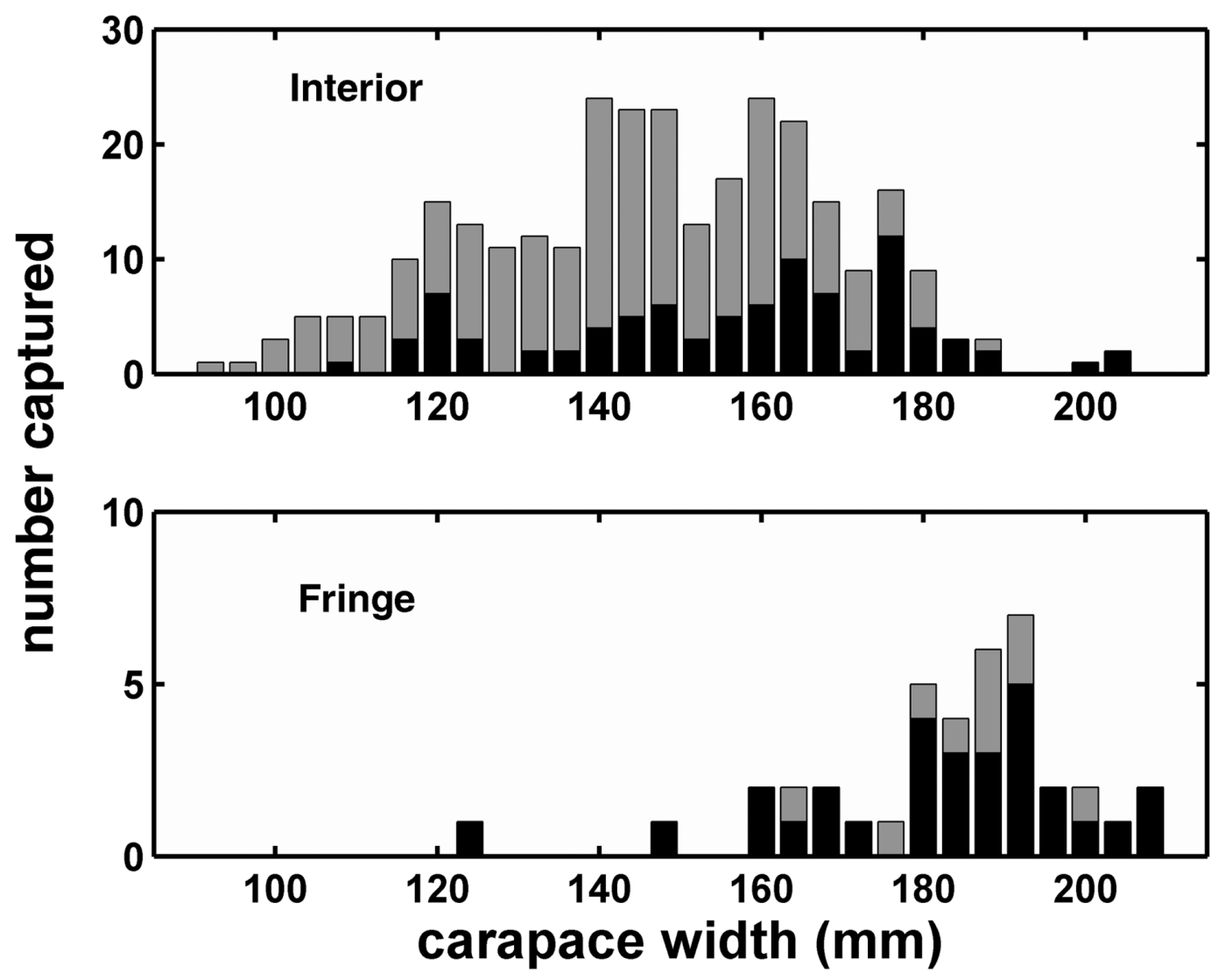

FIGURE 5. Size distribution of mangrove crabs captured in interior (upper panel) and fringe (lower panel) channels. Black bars indicate size distributions observed for Utwe-Isra only; gray bars indicate distributions for all sampled areas, including Utwe-Isra.

ferences tended to decline with sample size, particularly for females. Although the small number of crabs captured in Lelu Harbor limited evaluation of size-class structure and comparisons with other sectors, size-class distribution there appears to be consistent with the islandwide pattern and is perhaps most similar to that observed in nearby Pukusrik (Figure 6).

\section{Spatial Variation in Attrition Rates}

Attrition rates differed more sharply across transitions between smaller and larger size classes than among sectors, but the size class after which attrition rates increased varied substantially among sectors (Table 2, Figure
7). We did not detect significant spatial variation in attrition from either smaller or larger size classes. For Pukusrik and Okat, however, estimated attrition affecting the largest size classes was significantly higher than attrition affecting the smaller size classes (Table 2, Figure 7). A similar increase in attrition on the two largest size classes was apparent in Lelu Harbor and Utwe-Isra, but the presence of only two size classes constrained the precision of our estimate (Table 2, Figure 7).

\section{Catch-per-Unit-Effort}

We estimated Poisson capture rates of 0.592 crab trap ${ }^{-1}$ night $^{-1}(95 \%$ CI: $0.511,0.674)$ for male crabs, $0.161(0.121,0.210)$ for female 

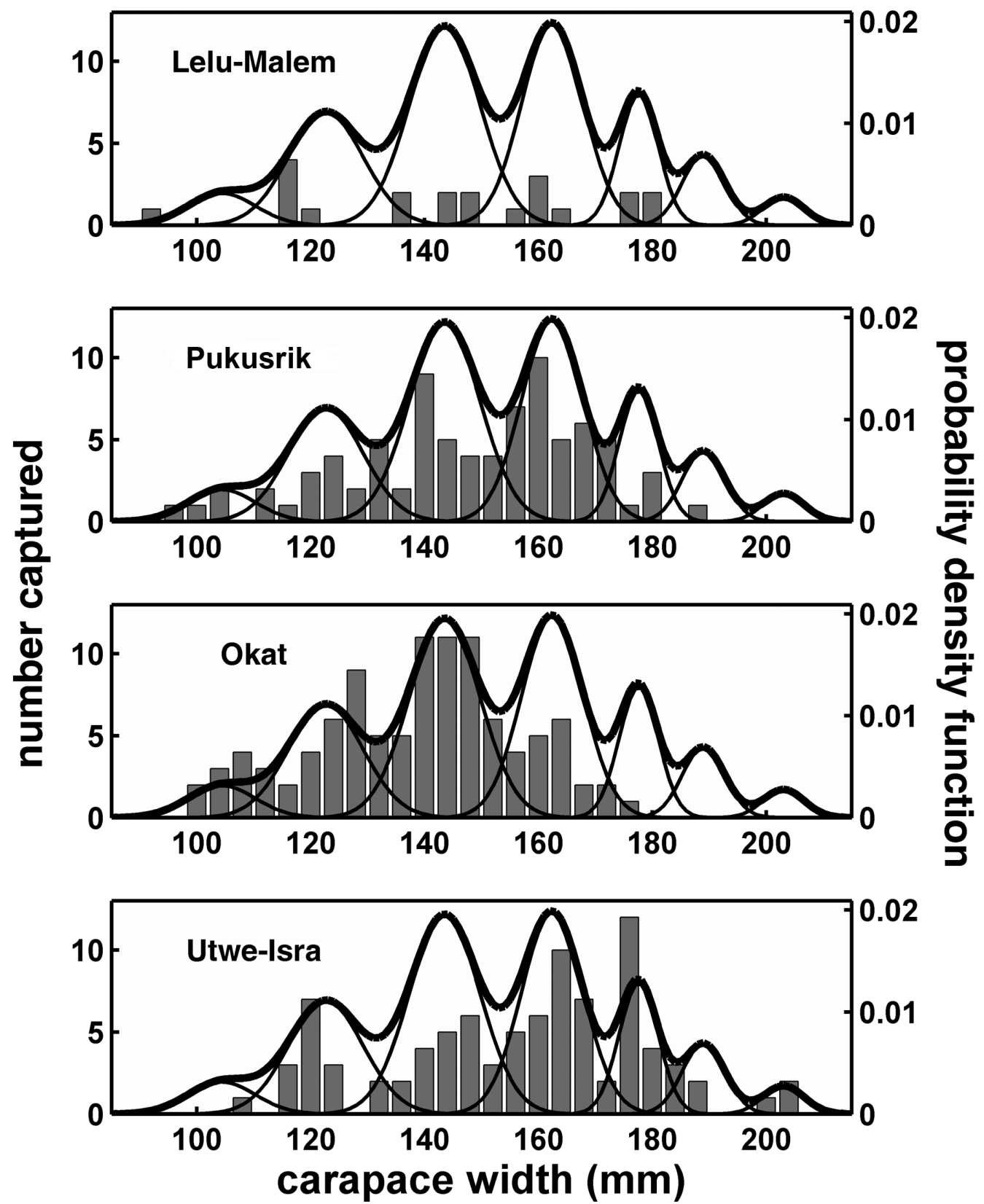

FIGURE 6. Variation in representation of size classes of mangrove crabs by sector. Bars (left $y$-axis) indicate actual counts of crabs in $4 \mathrm{~mm}$ size intervals for each sector. The thin and thick lines (right $y$-axis) are, respectively, the estimated size class-specific and composite distributions based on the islandwide analysis and illustrated in Figure 2. 
TABLE 2

Size Class-Specific Attrition Rates and Estimated Catch-per-Unit-Effort (CPUE) for Mangrove Crabs Captured in Interior Channel Habitats on Kosrae, FSM

\begin{tabular}{lllll}
\hline \hline Parameter & \multicolumn{1}{c}{ Lelu } & \multicolumn{1}{c}{ Pukusrik } & \multicolumn{1}{c}{ Okat } & \multicolumn{1}{c}{ Utwe-Isra } \\
\hline Attrition $\left(\%\right.$ days $\left.^{-1}\right)$ & $0.89(0.61,1.31)$ & $0.50(0.42,0.57)$ & $0.51(0.29,0.91)$ & $0.48(0.33,0.72)$ \\
Size classes $\left(\mathrm{mm}^{-1} \mathrm{CW}\right)$ & $104-178$ & $104-162$ & $104-144$ & $104-178$ \\
Attrition $\left(\%\right.$ days $\left.{ }^{-1}\right)$ & $5.38(0,99.95)$ & $3.27(2.27,4.69)$ & $3.08(2.30,4.13)$ & $2.04(0.24,15.31)$ \\
Size classes $(\mathrm{mm}$ CW $)$ & $189-203$ & $178-203$ & $162-203$ & $189-203$ \\
CPUE $(n /$ trap night $)$ & $0.50(0.31,0.76)$ & $0.95(0.75,1.19)$ & $0.85(0.68,1.05)$ & $0.63(0.49,0.79)$ \\
\hline
\end{tabular}

Note: Point estimates are followed in parentheses by upper and lower bounds on $95 \%$ confidence intervals for the estimated parameters. Size classes indicate the mean carapace width $(\mathrm{CW})$ of size classes for which the preceding attrition rate applies.
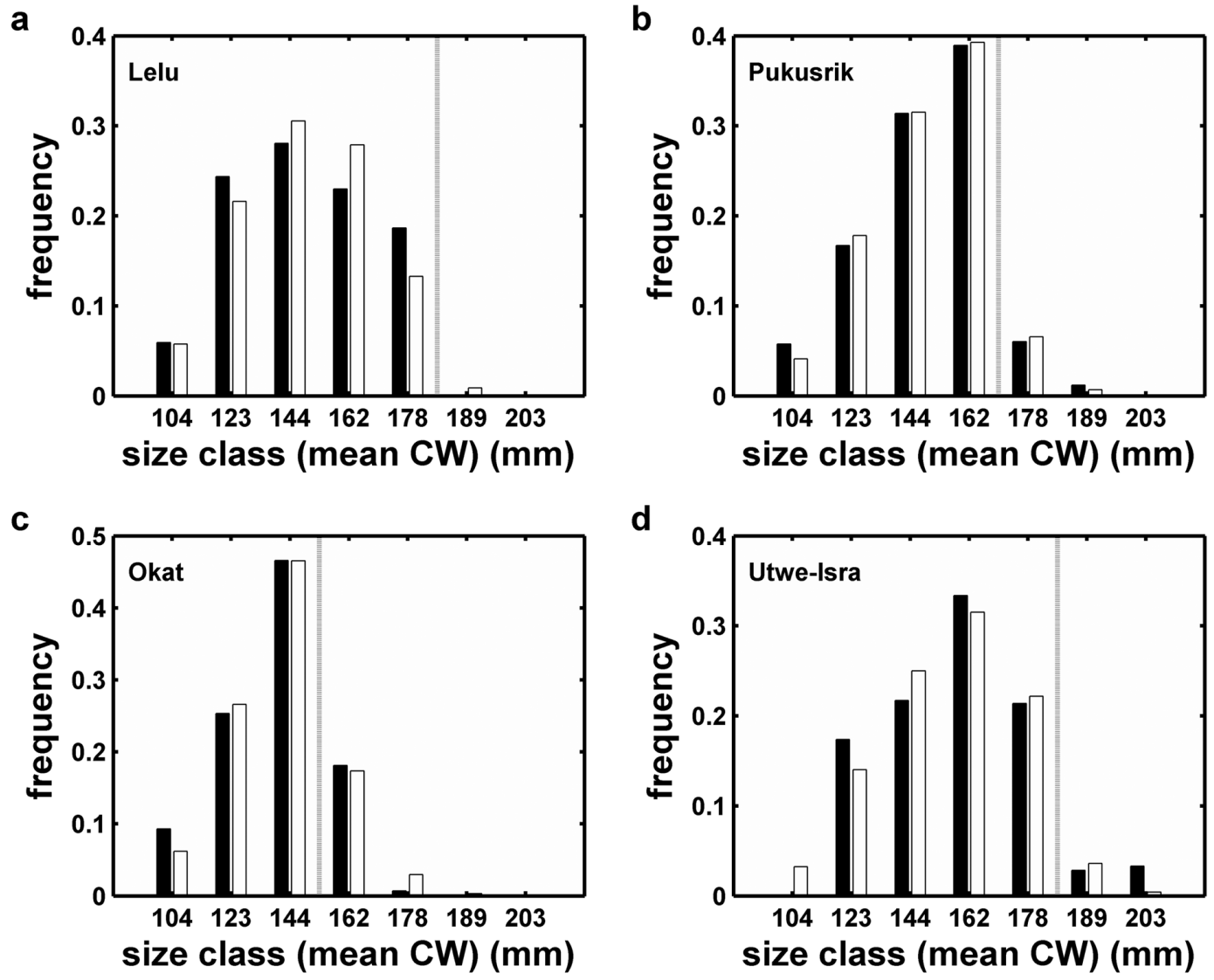

Figure 7. Observed (filled bars) and modeled (open bars) size-class distributions for S. serrata in four sectors of Kosrae, FSM. Model predictions are based on a stage-structured demographic model for S. serrata in interior channel habitats. Vertical gray lines indicate the transition between lower attrition rates on smaller size classes and higher attrition rates on larger size classes. Estimated attrition rates are provided in Table 2. 
crabs, and $0.754(0.661,0.846)$ for all crabs. We did not detect significant spatial variation in catch-per-unit-effort (Table 2), nor did we detect a significant variation in catch-perunit-effort over the course of the lunar cycle or the spring-neap tidal cycle (results not shown). Analysis of mean catch-per-uniteffort as a function of the number of traps in a set and as a function of trap position within a set validated our assumption that traps did not fish competitively when deployed along interior channels (results not shown).

\section{DISCUSSION AND CONCLUSIONS}

Mangrove crabs (Scylla serrata) on Kosrae, FSM, exhibit biological and ecological characteristics similar to those reported for the species elsewhere in its range: male crabs are about twice as heavy as females at a given carapace width (Figure 2) (Chakrabarti 1981); males outnumber females in areas that are more isolated from the open sea (Hill 1975, Perrine 1978, Nandi and Dev Roy 1990); individuals tend to move to seaward habitats as they grow (Figure 5) (Hill et al. 1982); adult $S$. serrata exhibit limited movement along the coastline (results from the tagging study) (Hill 1975, Perrine 1978, Pillans et al. 2005); and individual crabs can achieve a maximum size that exceeds $200 \mathrm{~mm}$ CW over a life span on the order of 3 to $4 \mathrm{yr}$ (Figure 4) (Le Vay 2001). Although we did not explicitly evaluate maturity of captured crabs, we observed no cases (e.g., large, immature crabs) that contradicted size-maturity relations reported elsewhere (Hill 1975, Perrine 1978, Heasman et al. 1985, Quinn and Kojis 1987, Prasad and Neelakantan 1989, Robertson and Kruger 1994, Robertson 1996). By demonstrating that $S$. serrata on Kosrae share traits with their conspecifics elsewhere our study implies that insights gained from research conducted in other parts of the species' range are relevant for developing effective management strategies for $S$. serrata on Kosrae. Perhaps more important, information about $S$. serrata on Kosrae, where it is the only mangrove crab species present, can be used unambiguously throughout the species' range, particularly in the tropics, where differences among the four newly divided species may not yet have been established.

We observed one previously unreported pattern in the Kosrae population: the presence of a distinct segment of the population that was substantially heavier than most other crabs for a given carapace width. Predictions of carapace width as a function of weight for these crabs suggest that these crabs were approaching maximum weight for their size and possibly nearing a molt (Figure 2). It remains unclear why an apparently bimodal distribution of weight in a size class rather than a more continuous distribution is observed. It is possible that our sampling was somehow biased toward crabs of low condition and high condition, and crabs of moderate condition were simply less available to our gear, say, by spending more time in deeper habitats because they can sustain the energetic costs of more extensive seaward movements for feeding while also avoiding predation, yet still have sufficient scope for growth (increase in mass) to warrant such effort.

Our study provides compelling evidence for the effects of harvest on the population of $S$. serrata on Kosrae by detecting spatial variation in attrition rates and catch-perunit-effort that can be related to the distribution of the human population and the presence of commercial fishing operations. That harvest is the source of this spatial variation is indicated by two patterns: (1) the increase in attrition rates between smaller and larger size classes, and (2) spatial variation in the size class that marked the onset of the higher attrition rates. Integrated over the life cycle, estimated attrition rates are highest in Lelu, followed in declining order by Okat, Pukusrik, and Utwe-Isra, which mirrors patterns of human accessibility of the mangrove forest (Table 2, Figure 7). Similarly, the general trend of increasing catch-per-unit-effort from Lelu Harbor to Utwe-Isra and Okat to $\mathrm{Pu}-$ kusrik is opposite the trend in estimated attrition rates (Table 2) and is consistent with the effect of historically high harvest rates (Lelu) and the location of commercial fisheries (Okat and Utwe-Isra). We know of no eco- 
logical mechanism that could cause molting rates to vary sufficiently among sectors to yield the observed differences in size-class distributions if attrition rates were constant across sectors.

The apparently contrary estimates of attrition rates and catch-per-unit-effort for UtweIsra appear to rebut our argument that variation in harvest underlies spatial variation in size structure of $S$. serrata on Kosrae. We expect that demographics provides a partial explanation for this pattern, in that the population in Utwe-Isra was dominated by larger crabs, which will normally be less abundant simply due to cumulative natural mortality even under unfished conditions. We believe, however, that in Utwe-Isra, attrition rates are in fact higher than our estimates suggestspecifically, that a broader range of size classes is exposed to attrition rates that include substantial harvest mortality - and that the apparent discrepancy simply reflects an unintended artifact of our sampling program. The reduced degree of male bias in the sex ratio of crabs and the greater abundance of larger crabs in general suggest that our habitat designation rules were confounded by the extensive presence of readily accessible, protected reef flat habitat surrounded by mangroves in Utwe-Isra and led to the inclusion of collections from "fringe-like" habitats in our "interior channel" observations. If this is the case, immigration of crabs of moderate size from more interior portions of the mangrove forest to the areas from which our samples were taken is likely to mask or offset the effects of harvest on population size structure in the areas sampled and thus lead to a relatively low estimate of attrition even though abundance (catch-per-unit-effort) has been reduced by harvest.

Our estimates of attrition rates were surprisingly high and substantially exceed the only estimate of natural mortality in S. serrata that we found reported in the literature (41$60 \% \mathrm{yr}^{-1}$ for populations in seasonal estuaries [Hill 1975] versus $82-96 \% \mathrm{yr}^{-1}$ smaller size classes and $>99 \% \mathrm{yr}^{-1}$ on larger size classes on Kosrae [this study]), yet we do not believe our estimates to be far off the mark. Indeed, because our definition of attrition subsumes natural mortality, mortality due to fishing, and net migration to the sampled habitat, we can expect our estimates of attrition to exceed natural mortality simply by definition. The question therefore becomes not only whether total rates of attrition are estimated correctly but also whether harvest, emigration, or other factors suffice to account for the disparity in rates.

We are confident that our estimates of attrition are sound and base this conclusion on the validity of the analyses upon which these estimates depend, namely our analysis of sizeclass distributions (Figures 3 and 6) and estimation of intermolt intervals (Figure 4). First, previous studies report size distributions that are qualitatively consistent with our observations and, in some cases, appear to indicate distributions in which size classes have been partly obscured by binning the data at a coarser resolution than used in our study (Hill 1975, Perrine 1978, Williams and Hill 1982, Robertson and Kruger 1994, Robertson 1996). Second, the observation of a linear relationship between the carapace widths at sequential size classes is consistent with patterns reported for numerous other crustacean species (Hiatt 1948, Caddy 2003), which lends further support to the conclusion that the multimodal size-class distribution reported here is real. Finally, our estimates of intermolt intervals are corroborated by independent observations of $S$. serrata from tropical regions (Arriola 1940, Perrine 1978) and lead to an estimated life span comparable with that reported for conspecifics elsewhere (Perrine 1978, Heasman 1980, Robertson 1996, Le Vay 2001). Indeed, we believe our analysis provides a reasonable prediction of average intermolt interval in a given size class, although individuals may exhibit longer intermolt intervals (Ong 1966, Perrine 1978). In any case, we note that any error in our estimate of intermolt intervals, say due to undetected tag losses, will affect our estimate of absolute attrition rate but will not affect spatial variation in relative attrition rates observed between sectors.

Although our analysis of spatial variation in attrition rates indicates that harvest is a major source of mortality of mangrove crabs 
on Kosrae, exactly how much harvest contributes to attrition is difficult to resolve with the available data. Measures of attrition rates and catch-per-unit-effort among the four sites mutually suggest that harvest effects are not negligible and are likely to be substantial (see also Naylor et al. 2002). Moreover, the similarity between our estimates of catch-perunit-effort and those reported for populations of S. serrata in South African estuaries considered to be too small to support a commercial fishery $\left(0.50-0.95 \mathrm{crabs}\right.$ trap $^{-1}$ night $^{-1}$ [this study]; 0-1.67 crabs trap $^{-1}$ night $^{-1}$ [Robertson 1996]) suggests that the crab population on Kosrae might not be able to sustain increased, or perhaps even current, levels of harvest. More work is needed to obtain more exact estimates of abundance, to quantify the effects of harvest at local scales as well as the scale of the entire population more precisely, and to understand how recruitment contributes to population persistence and sustainable rates of harvest. In any case, the concerns expressed by Kosraeans regarding the future status and sustainability of this important cultural and economic resource appear to be well justified.

Management of the fishery on mangrove crabs on Kosrae should focus on maintaining population productivity by reducing mortality rates of immature crabs and increasing survival of females so that they can reproduce at natural rates. In other crab populations (e.g., the Dungeness crab, Cancer magister) sizeand sex-specific harvest regulations protect female crabs and immature male crabs while allowing open harvest on mature males yet do not appear to compromise the productivity of a stock substantially (Hankin et al. 1997). Similar regulations have had a positive effect in Australian mud crab populations (Pillans et al. 2005) and should be considered for mangrove crabs on Kosrae. Evidence that harvest has localized effects and that adult crabs limit their alongshore movement suggests that an adaptive, comanagement strategy that incorporates reserves for mangrove crabs might be an effective tool for managing this species (e.g., Castilla and Defeo 2004, Pillans et al. 2005). Evidence for rapid local replenishment of larger size classes in crusta- ceans (Pillans et al. 2005; K.C.E., unpubl. data) suggests that a more sophisticated system of harvest "rotation" might allow adequate access to larger, more valuable crabs, but such a system would be more difficult to design, communicate, and enforce. Truly effective management of mangrove crabs, like any similar species that has a potentially dispersive larval stage, will require concerted attention to sustainable management at regional scales spanning populations that exchange recruits through larval dispersal (Mora and Sale 2002).

The status and dynamics of S. serrata described in this study provide a suitable basis for monitoring to evaluate the effectiveness of future management strategies on Kosrae. Using catch-per-unit-effort as a general population monitoring tool should be augmented by collection and analysis of size-class frequency data, which provide a responsive and meaningful measure of changes in population status (K.C.E., unpubl. data), and which could be readily implemented by local managers. The major challenge to effective long-term management and conservation of mangrove crabs will instead be in development of an appropriate management approach that incorporates new biological information to adjust harvest regulations appropriately while still accommodating the unique cultural aspects of Kosrae.

\section{ACKNOWLEDGMENTS}

We thank Rosamond Naylor, Burton Singer, Thomas J. Smith III, Thomas G. Cole, James Baldwin, Stacy Rowe, and Steve Ralston for useful discussions and advice during various phases of this work; two anonymous reviewers for their comments on the manuscript; and three anonymous reviewers for their comments on an early version of a manuscript based on this work. Thomas G. Cole provided Figure 1. We thank Simpson Abraham, Robert Hauff, Erick Waguk, and Madison Nena for organizational and logistical support, and Christo Artusio, Maxwell Salik, Jason Jack, Rikitari Lowary, and Holden Nena for assistance in the field. We are grateful to the many Kosraeans who reported 
tagged crabs or otherwise expressed their interest in the project.

\section{Literature Cited}

Arriola, F. J. 1940. A preliminary study of the life history of Scylla serrata (Forskål). Philipp. J. Sci. 73:437-454.

Brown, I. W. 1993. Mangrove crabs. Pages 611-642 in A. Wright and L. Hill, eds. Nearshore marine resources of the South Pacific: Information for fisheries management and development. Forum Fisheries Agency, Honiara, Solomon Islands.

Caddy, J. F. 2003. Scaling elapsed time: An alternative approach to modeling crustacean moulting schedules? Fish. Res. 63:73-84.

Castilla, J. C., and O. Defeo. 2004. Latin American benthic shellfisheries: Emphasis on co-management and experimental practices. Rev. Fish Biol. Fish. 11:1-30.

Caswell, H. 2001. Matrix population models. 2nd ed. Sinauer Associates, Sunderland, Massachusetts.

Chakrabarti, K. 1981. A growth study of the crab Scylla serrata Forsk. in the Sundarbans. Indian J. For. 4:102-106.

Chandrasekaran, V. S., and R. Natrajan. 1994. Seasonal abundance and distribution of seeds of mud crab Scylla serrata in Pichavaram mangrove, Southeast India. J. Aquacult. Trop. 9:343-350.

Ewel, K. C., R. D. Hauff, and T. G. Cole. 2003. Analyzing mangrove forest structure and species distribution on a Pacific island. Phytocoenologia 33:251-266.

FSM Census. 2002. 2000 FSM census of population and housing: Kosrae State census report. Kosrae Branch Statistics Office, Division of Statistics, Department of Economic Affairs, Kosrae, Federated States of Micronesia.

Hankin, D. G., T. H. Butler, P. W. Wild, and Q.-L. Xue. 1997. Does intense fishing on males impair mating success of female Dungeness crabs? Can. J. Fish. Aquat. Sci. 54:655-659.

Hasselblad, V. 1966. Estimation of parameters for a mixture of normal distributions. Technometrics 8 (3): 431-444.
Hauff, R. D., K. C. Ewel, and J. Jack. 2006. Tracking human disturbance in mangroves: Estimating harvest rates on a $\mathrm{Mi}$ cronesian island. Wetlands Ecol. Manage. 14:95-105.

Heasman, M. P. 1980. Aspects of the general biology and fishery of the mud crab Scylla serrata (Forskål) in Moreton Bay, Queensland. Ph.D. diss., University of Queensland, Queensland, Australia.

Heasman, M. P., D. R. Fielder, and R. K. Shepherd. 1985. Mating and spawning in the mudcrab, Scylla serrata (Forskål) (Decapoda: Portunidae), in Moreton Bay, Queensland. Aust. J. Mar. Freshwater Res. 36:773-783.

Hiatt, R. W. 1948. The biology of the lined shore crab, Pachygrapsus crassipes Randall. Pac. Sci. 2:135-213.

Hill, B. J. 1974. Salinity and temperature tolerance of zoeae of the portunid crab Scylla serrata. Mar. Biol. (Berl.) 25:21-24.

- 1975. Abundance, breeding and growth of the crab Scylla serrata in two South African estuaries. Mar. Biol. (Berl.) 32:119-126.

-1978. Activity, track, and speed of movement of the crab Scylla serrata in an estuary. Mar. Biol. (Berl.) 47:135-141.

1994. Offshore spawning by the portunid crab Scylla serrata (Crustacea: Decapoda). Mar. Biol. (Berl.) 120:379-384.

Hill, B. J., M. J. Williams, and P. Dutton. 1982. Distribution of juvenile, subadult and adult Scylla serrata (Crustacea: Portunidae) on tidal flats in Australia. Mar. Biol. (Berl.) 69:117-120.

Hyland, S. J., B. J. Hill, and C. P. Lee. 1984. Movement within and between different habitats by the portunid crab Scylla serrata. Mar. Biol. (Berl.) 80:57-61.

Knuckley, I. A. 1999. Mud crab (Scylla serrata) population dynamics in the Northern Territory, Australia, and their relationship to the commercial fishery. Ph.D. thesis, Northern Territory University, Darwin, Australia.

Le Vay, L. 2001. Ecology and management of mud crab (Scylla spp.). Asian Fish. Sci. 14:101-111.

Macnae, W. 1968. A general account of the 
fauna and flora of mangrove swamps and forests in the Indo-West Pacific region. Adv. Mar. Biol. 6:73-270.

Marichamy, R., and S. Rajapackiam. 2001. The aquaculture of Scylla species in India. Asian Fish. Sci. 14:231-238.

Mora, C., and P. F. Sale. 2002. Are populations of coral reef fish open or closed? Trends Ecol. Evol. 17:422-428.

Nandi, N. C., and M. K. Dev Roy. 1990. Burrowing activity and distribution of Scylla serrata (Forskål) from Hooghly and Matla estuaries, Sundarban, West Bengal. J. Bombay Nat. Hist. Soc. 88:167-171.

Naylor, R., and M. Drew. 1998. Valuing mangrove resources in Kosrae, Micronesia. Environ. Dev. Econ. 3:471-490.

Naylor, R. L., K. M. Bonine, K. C. Ewel, and E. E. Waguk. 2002. Migration, markets, and mangrove resource use on Kosrae, Federated States of Micronesia. Ambio 31:340-350.

Ong, K. S. 1966. Observations of the postlarval life history of Scylla serrata Forskål, reared in the laboratory. Malays. Agric. J. 45:429-443.

Perrine, D. 1978. The mangrove crab (Scylla serrata) on Ponape. Marine Resources Division, Ponape, East Caroline Islands, Trust Territory of the Pacific Islands.

Pillans, S., R. D. Pillans, R. W. Johnstone, P. G. Kraft, M. D. E. Haywood, and H. P. Possingham. 2005. Effects of marine reserve protection on the mud crab Scylla serrata in a sex-biased fishery in subtropical Australia. Mar. Ecol. Prog. Ser. 295:201213.

Prasad, P. N., and B. Neelakantan. 1989. Maturity and breeding of the mud crab, Scylla serrata (Forskal) (Decapoda: Brachyura: Portunidae). Proc. Indian Acad. Sci. Anim. Sci. 98:341-349.

Prasad, P. N., B. Neelakantan, and M. S. Kusuma. 1990. Distribution and abundance of the mud crab Scylla serrata from Karwar waters. Environ. Ecol. 8:798-804.

Quinn, N. J., and B. L. Kojis. 1987. Reproductive biology of Scylla spp. (Crustacea: Portunidae) from the Labu estuary in $\mathrm{Pa}$ pua New Guinea. Bull. Mar. Sci. 41:234241.
Robertson, W. D. 1996. Abundance, population structure and size at maturity of Scylla serrata (Forskål) (Decapoda: Portunidae) in Eastern Cape estuaries, South Africa. S. Afr. J. Zool. 31:177-185.

Robertson, W. D., and A. Kruger. 1994. Size at maturity, mating and spawning in the portunid crab Scylla serrata (Forskål) in Natal, South Africa. Estuarine Coastal Shelf Sci. 39:185-200.

Smith, A. J. 1992. Federated States of Micronesia marine resource profiles. FFA Report No. 92/17.

Triño, A. T., O. M. Mellamena, and C. Keenan. 1999. Commercial evaluation of monosex pond culture of the mud crab Scylla species at three stocking densities in the Philippines. Aquaculture 174:109-118.

Whitesell, C. D., C. C. Maclean, M. C. Falanruw, T. G. Cole, and A. H. Ambacher. 1986. Vegetation survey of Kosrae, Federated States of Micronesia. U.S. For. Serv. Resour. Bull. PSW 17:1-8.

Williams, M. J., and B. J. Hill. 1982. Factors influencing pot catches and population estimates of the portunid crab Scylla serrata. Mar. Biol. (Berl.) 71:187-192.

\section{Appendix}

Here we construct a simple stage-structured matrix model for the population of mangrove crabs susceptible to capture by traps, which we then use to develop sector-specific estimates of total mortality rates that might underlie spatial variation in size structure of mangrove crabs inhabiting interior mangrove channels around Kosrae. The model describes the dynamics for the seven size classes we observed in our collections, and has the form:

$$
\begin{aligned}
{\left[\begin{array}{c}
n_{1} \\
n_{2} \\
\vdots \\
n_{7}
\end{array}\right]_{t+1} } & {\left[\begin{array}{ccccc}
s_{1}\left(1-T_{12}\right) & 0 & \ldots & 0 & 0 \\
s_{1} T_{12} & s_{2}\left(1-T_{23}\right) & 0 & \ldots & 0 \\
0 & s_{2} T_{23} & \ddots & & \vdots \\
\vdots & & \ddots & s_{6}\left(1-T_{67}\right) & 0 \\
0 & \ldots & 0 & s_{6} T_{67} & s_{7}
\end{array}\right] } \\
& \times\left[\begin{array}{c}
n_{1} \\
n_{2} \\
\vdots \\
n_{7}
\end{array}\right]_{t}+\left[\begin{array}{c}
7 \\
0 \\
\vdots \\
0
\end{array}\right]
\end{aligned}
$$

where the $n$ terms describe abundance in each of the seven size classes observed in our trap data, the $T_{i j}$ terms describe the probability of a crab in size class $i$ molting and making the transition to size class $j, s_{i}$ is the size 
class-specific probability of survival, and $\mathcal{f}$ describes the (constant) rate of recruitment by juvenile crabs to the smallest observable size class. All rates and probabilities are specified at a daily time scale. We used numerical simulation to calculate the stable size-class distribution (Caswell 2001) and assume that any density-dependent mechanisms affect the population dynamics in such a way that a stable steady state exists and that the stable size-class distribution achieved at this steady state is identical to that reached under density-independent dynamics with $R=1$ (i.e., a constant population size). By fitting frequency distributions, rather than abundances, we effectively factor out the effects of recruitment and can focus solely on attrition rates.

Our data suggest that crabs' availability or susceptibility to capture in traps increases with size. We therefore assume that crabs smaller than $80 \mathrm{~mm}$ carapace width $(\mathrm{CW})$ are either not available in the sampled habitats or are not susceptible to capture and that availability or susceptibility increases with size to the point that crabs in the $143 \mathrm{~mm}$ CW size class are fully available and susceptible to capture. We accommodated this pattern in the course of fitting the model to the data by specifying and applying an arbitrary capture ogive of the form [0.2 0.6

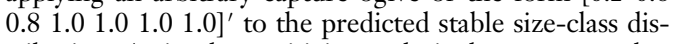
tribution. A simple sensitivity analysis demonstrates that reasonable variation in the capture ogive does not substantially affect variation among sector-specific estimates of attrition rates (results not shown).

We estimate total mortality rates $\left(s_{i}=1-m_{i}\right)$ by fitting predictions for catchability-corrected stable sizeclass distributions to observed size-class distributions, in which each crab is assigned to a size class based on its carapace width and the size-class distribution identified as described in the text of the paper. Both observed and predicted stable size-class distributions were expressed as frequency distributions to avoid the need to estimate a recruitment term. Based on patterns apparent from visual inspection of the size-class distributions, we arbitrarily broke each size-class distribution into a group of small size classes and a group of large size classes and fit a separate attrition rate to each group. Parameter estimates were obtained using the "nlinfit" function in Matlab (R2006b 7.3 http://www.mathworks.com). 
